\title{
Analysis of the Russian Olympian Ski Jumpers' Technical Fitness on the Basis of Information Database
}

\author{
Zebzeyev V.V. \\ Tchaikovsky State Physical Education Institute \\ Tchaikovsky, Russia \\ zebzeev85@mail.ru
}

\author{
Zdanovich O.S. \\ Tchaikovsky State Physical Education Institute \\ Tchaikovsky, Russia \\ solic8233@yandex.ru
}

\begin{abstract}
At the moment many experts, coaches and athletes in ski jumping are focused on search of the most effective ways allowing to increase quality of the training process. At the same time computer technologies are integral part of sport for a long time and are actively used in ski jumping. The aim of the research was to analyze the indicators of the Russian national team in ski jumping members technical fitness on the basis of information database. Examples of the technical fitness analysis are shown on three athletes of the Russian national team who took part in the Winter Olympic Games in Sochi. It is established that the athlete M.M. has erred in flight and contact landing phases (he has insufficiently inclined his trunk). The athlete I.H. has erred in non-contact take-off, flight and contact landing phases (insufficient extension of ankle joint and trunk bending).
\end{abstract}

Keywords-ski jumping; jumping technique; information database; kinematic analysis.

\section{INTRODUCTION}

At present management of athletes fitness is impossible to imagine without a systematic control of athletes' fitness and analytics of the results obtained [2, 12]. At the same time the effectiveness of these processes depends largely on the quality of collecting, systematization and keeping the information obtained on condition of investigating objects. Computer processing, collection and storage of athletes' fitness controlled indicators allows ultimately to create database, and this information is the foundation for a coach for effective management of the training process [15].

The efficiency of this approach was demonstrated by professor B. Jost at the University of Ljubljana. He developed the information database (he calls it "system of expert assessment") and implemented it in the training process of the Slovenian ski jumpers $[8,9]$.

However, in the Russian ski jumping the database, unfortunately, is not still established and used (till not old time actively were not used). Although their systematic use would allow, on the one hand, to treat quickly the extensive data on the current status of athletes, on the other hand, to develop a model of the of athletes' fitness different sides characteristics at different age, sex, skills that would let significantly improve the existing system of sports selection in ski jumping and Nordic combined.

\section{METHODS}

Study and generalization of the scientific-methodical literature; pedagogic observation; video filming with the video analysis on the basis of the software Dartfish (version 4.0). They were carried out according to the recommendations stated in a number of scientific works [3, $4,7,12,13,14]$. For creation of information database the software Microsoft Access 2016 was used. As example of carrying out the comparative analysis of technical ski jumpers' fitness video records of three jumps, executed by athletes of the Russian national team from jumping hill (K95) $(02 / 08 / 2014)$ at the Winter Olympic Games are used. The research of technical athletes' fitness performed on kinematic indicators (to angles between various parts of the athletes' body and the horizon) in in-run, contact take-off, non-contact take-off, flight, non-contact landing and contact landing phases carrying out comparison of the actual results with model characteristics $[10,11]$.

\section{RESULTS}

On the basis of the software we developed the information database which consists of 6 sections and contains information on morphological features of the athletes' body structure, about the most important parameters of competitive activity, indicators of technical, physical, functional fitness of ski jumpers and their dynamics during not only the current competitive season but also the Olympic cycle. Compound component of the database are model characteristics of technical fitness and competitive activity of ski jumpers.

In this scientific work, proceeding from the maintenance of our research a subject, we have involved only 3 blocks of ID containing data on indicators of athletes technical and competitive fitness. 
On the example of results in the first trial of two athletes, who took part in the Russian national team at the Winter Olympic in Sochi, we will analyze indicators their technical fitness and competitive performance on the basis of created information database.

The comparative analysis of the ski jumper M.M. actual technical fitness indicators with model characteristics has shown that angular characteristics of the carried out jump technique corresponded practically to model indicators in phases of in-run $\left(\alpha_{\mathrm{IR}}, \beta_{\mathrm{IR}}, \varphi_{\mathrm{IR}}\right)$, contact take-off $\left(\alpha_{\mathrm{CT}}, \alpha_{1 \mathrm{CT}}\right.$, $\left.\beta_{\mathrm{CT},}, \varphi_{\mathrm{CT}}\right)$, non-contact take-off $\left(\omega_{\mathrm{NT}}, \alpha_{\mathrm{NT}}, \varphi_{\mathrm{NT}}\right)$ and noncontact landing $\left(\omega_{\mathrm{NL}}, \varphi_{\mathrm{NL}}\right)$.

However, comparison of angular characteristics in flight phase allowed to make the conclusion that the athlete made a small mistake of inclining his trunk insufficiently, deviation size in angle was 8 degrees.

At the same time the investigated athlete bent legs in ankle joint $\left(\alpha_{\mathrm{F}}\right)$ insufficiently that has negatively impact on his aerodynamic position in relation to the horizon $\left(\omega_{\mathrm{F}}\right)$.

Research of deviations in contact landing phase has shown that the athlete has committed errors when bending legs in ankle joint $\left(\alpha_{\mathrm{CL}}, \alpha_{1 \mathrm{CL}}\right)$ and insufficient trunk bending $\left(\varphi_{\mathrm{CL}}\right)$. The committed errors in the flight and contact landing phases, unfortunately, had negatively impact on judges' points and total scoring for jump. So, total scoring for jump was 10,4 points less than model values that allowed the jumper M.M. to place only 10-th.

Comparison of the ski jumper I. Kh. actual technical fitness indicators with model characteristics showed that angular characteristics of the carried out jump technique corresponded practically to model indicators only in in-run, contact take-off and non-contact landing phases. Essential divergences of actual angular characteristics values with model were fixed in the following indicators of non-contact take-off, flight and contact landing: the angle $\alpha_{\mathrm{OT}}$ was lower than norm by 12 degrees, the angle $\varphi_{\text {От }}$ - by 11 degrees, the angle $\omega_{\mathrm{F}}$ - by 10 degrees, the angle $\alpha_{\mathrm{F}}$ - by 12 degrees, the angle $\alpha_{\mathrm{CL}}$ - by 24 degrees, the angle $\alpha_{1 \mathrm{CL}}$ - by 20 degrees, the angle $\varphi_{\mathrm{CL}}-$ by 10 degrees. The analysis of the indicators obtained allows to speak about that this athlete committed errors connected with insufficient extension of ankle joint and trunk bending in the phases of non-contact take-off and flight. The committed errors in technique jump significantly had impact on indicators of competitive activity: total jump length was less modal values by 11 meters, judicial points were less by 8,5 points and total scoring - by 25,2 points. The results obtained has allowed to place only 35 -th.

The comparative analysis of sky jumpers technical fitness which is carried out by us is made according to number of scientific works [1, 3, 7, 12, 14], in which kinematic indicators of athletes jump technique in different phases are similarly investigated. At the same time information technologies are important component of preparation in ski jumping for a long time by means of which scientists have opportunity to investigate recent trends in jump technique $[5,6]$. However, in the majority of scientific works the use of information technologies is limited only with use special computer programs. They are allowing to estimate and analyze one-time kinematic indicators of jump technique, but not giving the chance to estimate technical fitness of athletes systemically and to carry out the comparative analysis of jump technique kinematic indicators for a long time $[10,11]$. Thus, there is a need of the common computer program creation. It would help coaches and athletes to carry out comparison of actual indicators in fitness of one or several athletes with model characteristics (to carry out comparison of several athletes among themselves), based on it to correct process of jump technique formation taking into account specific features of each athlete.

The presented examples the Russian sky jumpers' technical fitness comparative analysis with use of information database allow to say that M.M. should place an emphasis on the use of the various imitating exercises and training simulators in his training process promoting improvement of jump technique in the flight and contact landing phases. The athlete I. Kh. should have much paid attention to improvement of jump technique in the noncontact take-off, flight and contact landing phases before preparation for the main competitions.

\section{CONCLUSION}

At present information technologies are integral part of modern sport. One of the computer programs types which were widely adopted in sports practice are information database. They are actively used for the purpose of effective management, control and correction of athletes' training. The developed database allows to store information on the most important morphological indicators, criteria of competitive activity and parameters of technical, physical, functional fitness of ski jumpers of different qualification and their dynamics during not only the current competitive season, but also the Olympic cycle. Carrying out the comparative analysis of three ski jumpers technical fitness indicators who are part of the Russian national team and took part in competitions at the Winter Olympic Games in Sochi with using of information database has allowed to reveal faults in technique of each athlete in various phases of jump.

\section{References}

[1] Arndt, A., Brügemann, G.-P., Virmavirta, M., \& Komi, P. V. Techniques used by Olympic ski jumpers in the transition from take off to early flight. Journal of Applied Biomechanics. 1995, 11(2), pp. 224-237.

[2] Bosl, P., Schwirtz, A., Rott F., \& Grosgebauer, J. Comparison of lower limb strength between athletes in ski jumping and Nordic combined. In V. Linnamo, P. V. Komi, \& E. Muller (Eds.), Science and Nordic Skiing. 2007, pp. 183-190.

[3] Bruggemann, G.-P., DeMonte, G., Komi, P. V., Iso lehto, J., Muller, E., Potthast, W., Schwameder, H., \& Virmavirta, M. Biomechanical analysis of the take off, the early and the mid flight phases in ski jumping during the Salt Lake City Winter Games. Medicine \& Science in Sports \& Exercise. 2002, 34(5), pp. 123.

[4] Denoth, J., Luethi, S. M., \& Gasser, H. H. (1987). Methodological problems in optimization of the flight phase in ski jumping. International Journal of Sport Biomechanics, 3, 404-418. 
[5] Ito, S., Seo, K., \& Asai, T. An experimental study on ski jumping styles. In M. Estivalet, \& P. Brisson, (Eds.), The Engineering of Sport. 1987, 7(2), 9-17.

[6] Janura, M., Svoboda, Z. \& Uhlař, R. A comparison of ski jump execution in a group of the best jumpers. In V. Linnamo, P. V. Komi, \& E. Muller (Eds.). Science and Nordic skiing. 2007, pp. 205214.

[7] Janura, M., Cabell, L., Svoboda, Z., Elfmark, M., \& Janurová, E. Analysis of the beginning of the early flight phase of the ski jump in athletes with different performance levels. Acta Universitatis Palackianae Olomucensis. Gymnica. 2011, 41(3), pp. 7-13.

[8] Jost, B. \& Coh, M. Expert modeling of sport performance of high elite athletes. Acta Kinesiologica. 2014, 8, pp. 82-85.

[9] Jost, B. Some model characteristics of ski jumpers found with the standard procedure and with a method of expert modeling. Kinesiologia Slovenica, 1998, 1(1), pp. 39-42.

[10] Jost, B. (2014). Expert system for evaluation of Ski jumpers Champion performance. URL: http://www.skijumpingrus.ru/data/files/16/Prezentaciya Boyan_Yost perevod_ch.2.pdf

[11] Jost, B. (2014). Technics of skijumping. URL: http://www.skijumpingrus.ru/data/files/16/Prezentaciya Boyan_Yost ch.1.pdf

[12] Jošt, B., Čoh, M., Pustovrh, J., \& Ulaga, M. Analysis of the selected kinematic variables of the take off in ski jumps and their correlation with the length in the finals of the world cup at Planica in 1999. In M. Čoh \& B. Jošt (Eds.). Biomechanical characteristics of technique in certain chosen sports. 2000, pp. 58-71.

[13] Komi, P. V., Nelson, R. C., \& Pulli, M. Biomechanics of ski jumping. Studies in Sport Physical Education and Health. 1974, 5, pp. $1-53$.

[14] Schwameder, H. Biomechanics research in ski jumping - 19912006. Sports Biomechanics. 2008, 7(1), pp. 114-136.

[15] Zebzeev, V.V. \& Zdanowich, O.S. Highly-skilled Nordic combined skiers' integrated fitness control database. Theory and Practice of Physical Culture. 2016, 1, pp. 78-82.

[16] Aleksandr S. Kuznetsov. Russian Professor's meeting. Russian Journal of Physical Education and Sport. 2019, vol. 14(1), pp. 17-22. DOI: 10.14526/2070-4798-2019-14-1-18-24.

[17] Aleksandr S. Kuznetsov, Evgeniya N. Usmanova, Oksana V. Kolomytseva. Athletes' psychological-physiological indices study in different specializations at the stages of sports career crises overcoming. Russian Journal of Physical Education and Sport. 2019, vol. 14(2), pp. 81-87. DOI: 10.14526/2070-4798-2019-14-2-89-96. 